\section{Case Reports in Neurology}

\title{
Perfusion-Based Decision-Making for Mechanical Thrombectomy in a Transient Ischemic Attack Patient with Middle Cerebral Artery Occlusion
}

\author{
Thang Huy Nguyen ${ }^{a, b}$ Binh Nguyen Pham ${ }^{a} \quad$ Hoang Thi Phan $^{a, b}, c$ \\ Trung Quoc Nguyen ${ }^{\mathrm{a}} \quad$ Bau Van Phan ${ }^{\mathrm{a}}$ \\ ${ }^{a}$ Cerebrovascular Disease Department, 115 People's Hospital, Ho Chi Minh City, Vietnam; \\ bPham Ngoc Thach University of Medicine, Ho Chi Minh City, Vietnam; 'Menzies Institute \\ for Medical Research, University of Tasmania, Hobart, TAS, Australia
}

\section{Keywords}

Acute ischemic stroke - Mechanical thrombectomy · Transient ischemic attack · Minor stroke · Large-vessel occlusion

\begin{abstract}
A significant proportion of patients with large-vessel occlusion (LVO) initially present to the hospital with transient ischemic attack (TIA) and mild clinical manifestations such as low National Institutes of Health Stroke Scale (NIHSS) scores $(\leq 5)$. However, due to the natural course of the disease, the individuals may subsequently develop worsening symptoms. To date, there is lack of evidence-based guidelines on mechanical thrombectomy (MT) among those patients. Therefore, the predicting factors associated with better or worse outcomes for acute stroke patients receiving MT compared to those not receiving the treatment are unknown. We describe a TIA case with LVO who was treated with MT; we used perfusion imaging as a decision aid. A 55-year-old male patient with a past medical history of TIA, hypertension, and hyperlipidemia was admitted to our hospital for evaluation of transient mild right hemiparesis and dysarthria lasting for $5 \min 3 \mathrm{~h}$ before admission. He reported that he had experienced the
\end{abstract}

\begin{tabular}{ll}
\hline & Bau Van Phan \\
Cerebrovascular Disease Department, 115 People's Hospital \\
\\
527 Su Van Hanh Street, District 10 \\
Ho Chi Minh City (Vietnam) \\
bauphanv@gmail.com
\end{tabular}




\section{Case Reports in Neurology}

Case Rep Neurol 2020;12:41-48

\begin{tabular}{l|l}
\hline DOI: 10.1159/000507753 & $\odot 2020$ The Author(s). Published by S. Karger AG, Basel
\end{tabular} www.karger.com/crn

Nguyen et al.: Mechanical Thrombectomy in a TIA Patient with Middle Cerebral Artery Occlusion

same condition 1 day before. On admission, neurological examination showed normal function with an NIHSS score of 0 . Computed tomography angiography revealed left proximal M1 occlusion. In addition, perfusion magnetic resonance imaging maps calculated by the RAPID software showed acute small lesions on the left hemisphere with core volume $(0 \mathrm{~mL})$ and a large ischemic penumbra $(70 \mathrm{~mL}$ ). Immediate endovascular thrombectomy was performed $5 \mathrm{~h}$ following symptom onset with complete recanalization and clinical recovery. The case suggests that MT in LVO patients with low NIHSS scores, even a score of 0 , on presentation is potentially a safe and effective treatment. The use of perfusion imaging in the acute phase of stroke should be encouraged for the decision-making process.

\section{Introduction}

Recently, data from several randomized clinical trials demonstrated clear benefits of mechanical thrombectomy (MT) in patients with National Institutes of Health Stroke Scale (NIHSS) threshold $\geq 6$ and acute ischemic stroke caused by a large-vessel occlusion (LVO) in the anterior circulation [1]. However, whether the same benefit exists for a less frequent but more specific population group - acute stroke patients with LVO presenting with transient ischemic attack (TIA) and/or mild clinical symptoms (e.g., low NIHSS scores) - has not been well established. This can pose substantial challenges in diagnosis, treatment, and disease management. Due to the dilemmas, a large proportion of those patients may not be considered for recanalization procedure, particularly those presenting with mild neurological deficits. However, the patients are at risk of subsequent neurological worsening and may end up with poor outcomes. Perfusion imaging has a growing role in evaluating tissue viability and mismatch at the time of patient presentation, hence it can help make appropriate treatment decisions. Here, we present a TIA patient with LVO who was successfully treated with MT guided by perfusion imaging.

\section{Case Presentation}

A 55-year-old male patient with a past medical history of TIA, hypertension, and hyperlipidemia presented to our hospital for evaluation of transient mild right hemiparesis and dysarthria lasting for $5 \mathrm{~min} 3 \mathrm{~h}$ before admission. No other vascular risk factors were recognized. He had experienced similar symptoms 1 day before. On admission, neurological examination showed normal finding with an NIHSS score of 0, and blood pressure was 160/90 mm Hg. Cerebral computed tomography (CT) revealed no intracranial hemorrhage and an Alberta Stroke Program Early CT Score (ASPECTS) of 10 in the left middle cerebral artery (MCA) territory (Fig. 1a). CT angiography revealed left proximal M1 occlusion and good collateral status (Fig. 1b). We also performed a "stress test" by sitting the patient upright for $10 \mathrm{~min}$ and then evaluating for any deterioration. The patient passed the test and tolerated walking. Since all clinical symptoms disappeared, perfusion magnetic resonance imaging (MRI) was performed to evaluate mismatch volume and the risk of deterioration. Perfusion MRI maps calculated by the RAPID software showed small lesions on the left hemisphere with core volume $(0 \mathrm{~mL})$, a large ischemic penumbra (70 mL), and mismatch volume (70 mL) (Fig. 2a, b). Different-aged hyperintensity lesions were recorded on diffusion-weighted imaging, suggesting that the

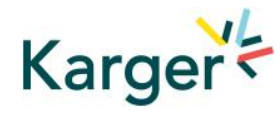




\section{Case Reports in Neurology}

Case Rep Neurol 2020;12:41-48

\begin{tabular}{l|l}
\hline DOI: 10.1159/000507753 & $\odot 2020$ The Author(s). Published by S. Karger AG, Basel
\end{tabular} www.karger.com/crn

Nguyen et al.: Mechanical Thrombectomy in a TIA Patient with Middle Cerebral Artery Occlusion

patient had recent ischemic stroke. Therefore, no systemic thrombolysis was administered. Furthermore, in the presence of large mismatch volume, the patient underwent MT treatment, with an onset-to-groin puncture time of $6 \mathrm{~h}$. Five passes of stent retriever fully extracted the thrombus and led to complete recanalization of the MCA segment (Fig. 3a-c). During hospitalization, the patient was in stable condition without neurological deficits. His blood pressure dropped back to $130 / 80 \mathrm{~mm} \mathrm{Hg}$ and was maintained below 140/90 $\mathrm{mm} \mathrm{Hg}$ due to successful reperfusion. Another follow-up perfusion MRI at $24 \mathrm{~h}$ showed no more mismatch and complete recanalization of left MCA (Fig. 4a, b). The clot specimen evaluated by histopathology was composed mostly of fibrin and cholesterol crystals. Other test results included high LDLC lipid profile, nonsignificant carotid artery stenosis, sinus rhythm on electrocardiogram, and normal heart ultrasound, which confirmed the atherosclerosis cause of the vascular occlusion. The patient was discharged on the 7th day of hospitalization with antiplatelet therapy, high dose of statin, and other cardiovascular risk factor control therapies.

\section{Discussion}

TIA and minor stroke patients with LVO are at high risk of symptom progression and poor functional outcome $[2,3]$. Approximately $10 \%$ of patients initially present to the hospital with TIA or minor strokes, which are affected by early progression of symptoms and infarct growth in association with LVO [4, 5]. Heldner et al. [6] reported that without thrombolysis or MT treatment, $22.7 \%$ of patients with LVO and low NIHSS scores experienced deterioration within $24 \mathrm{~h}, 33.3 \%$ deteriorated during hospital stay, and $41.4 \%$ deteriorated within 3 months, and $6.7 \%$ of them deceased. One aspect to consider in TIA patients with LVO is the collateral status. Patients with LVO presenting with TIA are more likely to have adequate collateral circulation to minimize brain damage. Our patient presented with an NIHSS score of 0 , suggesting a good collateral circulation. However, Miteff et al. [7] showed that only 38\% of those with good collateral status but poor reperfusion had favorable outcomes. In addition, Campbell et al. [8] demonstrated that collateral deterioration between baseline and follow-up imaging was strongly associated with infarct growth. Therefore, the existence of good collaterals does not warrant a good outcome and reperfusion is still of utmost importance. Current clinical guidelines on MT recommend a lower NIHSS threshold of 6, but they are mostly based on clinical trials. To date, guidelines on MT among LVO patients with low NIHSS scores are lacking. Only observational studies and case series were conducted using mostly ASPECTS and CT angiography/magnetic resonance angiography as the proof of LVO and ischemic core volume. Importantly, several factors need to be taken into account in decision-making for MT, including the risk of neurological deterioration and clinical outcomes versus the complication rate of the procedure (e.g., displacement of the embolus causing distal occlusion and thus worsening neurological deficits). The problem is how we can predict which one that will be. Some have suggested sitting up the patient as a "stress test" to observe whether the clinical manifestations get worse. Another option is to monitor the patient tightly and immediately perform MT in case of deterioration. Some studies showed that approximately one-third of patients with TIA or minor stroke still have tissue hypoperfusion [9-12]. Neurological deterioration is therefore likely due to the growth of ischemic core into the penumbra. It seems that using perfusion imaging to define the ischemic penumbra would be a better approach. In perfusion MRI, a large mismatch volume of $70 \mathrm{~mL}$ was estimated, which indicated benefit from endovascular recanalization. Cerebral distraction angiography revealed proximal left M1

\section{Karger'=}




\section{Case Reports in Neurology}

Case Rep Neurol 2020;12:41-48 DOI: $10.1159 / 000507753$

(c) 2020 The Author(s). Published by S. Karger AG, Basel www.karger.com/crn

Nguyen et al.: Mechanical Thrombectomy in a TIA Patient with Middle Cerebral Artery Occlusion

occlusion. Angiography at the end of the intervention also showed complete reperfusion of the former occluded left MCA territory (TICI 3), and disappearance of mismatch volume on 24-h follow-up perfusion MRI reconfirmed the proper perfusion-based clinical decisionmaking.

In conclusion, the presence of significant perfusion MRI diffusion mismatch among TIA/ minor stroke patients with LVO would likely benefit from MT treatment. Therefore, further studies, particularly randomized controlled trials, are needed to focus on this population group and will help provide long-term efficacy data.

\section{Acknowledgment}

We acknowledge Dr. Vu Thanh Tran and Dr. Tri Quang Nguyen for providing treatment, patient data, and their assistance with interpretation of the images in this paper.

\section{Statement of Ethics}

Written informed consent was obtained from the patient for publication of his case and any accompanying images.

\section{Conflict of Interest Statement}

The authors have no conflicts of interest to declare.

\section{Funding Sources}

The authors received no financial support for the research, authorship, or publication of this article.

\section{Author Contributions}

T.H. Nguyen and B.N. Pham were major contributors in writing the manuscript and performing the literature review. H.T. Phan and T.Q. Nguyen made substantial contributions in revising the manuscript and interpreting part of the patient data. B.V. Phan supervised the study, interpreted the patient data, and was a major contributor in writing the manuscript. All authors read and approved the final manuscript. 


\section{Case Reports in Neurology}

\section{References}

1 Goyal M, Menon BK, van Zwam WH, Dippel DW, Mitchell PJ, Demchuk AM, et al.; HERMES collaborators. Endovascular thrombectomy after large-vessel ischaemic stroke: a meta-analysis of individual patient data from five randomised trials. Lancet. 2016 Apr;387(10029):1723-31.

2 Horton M, Modi J, Patel SK, Demchuk AM, Goyal M, Hill MD, et al. Refinement of Imaging Predictors of Recurrent Events following Transient Ischemic Attack and Minor Stroke. PLoS One. 2013 Jun;8(6):e65752.

3 Coutts SB, Modi J, Patel SK, Demchuk AM, Goyal M, Hill MD; Calgary Stroke Program. CT/CT angiography and MRI findings predict recurrent stroke after transient ischemic attack and minor stroke: results of the prospective CATCH study. Stroke. 2012 Apr;43(4):1013-7.

4 Rajajee V, Kidwell C, Starkman S, Ovbiagele B, Alger JR, Villablanca P, et al. Early MRI and outcomes of untreated patients with mild or improving ischemic stroke. Neurology. 2006 Sep;67(6):980-4.

5 Asdaghi N, Hill MD, Coulter JI, Butcher KS, Modi J, Qazi A, et al. Perfusion MR predicts outcome in high-risk transient ischemic attack/minor stroke: a derivation-validation study. Stroke. 2013 Sep;44(9):2486-92.

6 Heldner MR, Jung S, Zubler C, Mordasini P, Weck A, Mono ML, et al. Outcome of patients with occlusions of the internal carotid artery or the main stem of the middle cerebral artery with NIHSS score of less than 5: comparison between thrombolysed and non-thrombolysed patients. J Neurol Neurosurg Psychiatry. 2015 Jul;86(7):755-60.

7 Miteff F, Levi CR, Bateman GA, Spratt N, McElduff P, Parsons MW. The independent predictive utility of computed tomography angiographic collateral status in acute ischaemic stroke. Brain. 2009 Aug;132(Pt 8): 2231-8.

8 Campbell BC, Christensen S, Tress BM, Churilov L, Desmond PM, Parsons MW, et al.; EPITHET Investigators. Failure of collateral blood flow is associated with infarct growth in ischemic stroke. J Cereb Blood Flow Metab. 2013 Aug;33(8):1168-72.

9 Prabhakaran S, Patel SK, Samuels J, McClenathan B, Mohammad Y, Lee VH. Perfusion computed tomography in transient ischemic attack. Arch Neurol. 2011 Jan;68(1):85-9.

10 Restrepo L, Jacobs MA, Barker PB, Wityk RJ. Assessment of transient ischemic attack with diffusion- and perfusion-weighted imaging. AJNR Am J Neuroradiol. 2004 Nov-Dec;25(10):1645-52.

11 Tong T, Yao Z, Feng X. Combined diffusion- and perfusion-weighted imaging: a new way for the assessment of hemispheric transient ischemic attack patients. Int J Dev Neurosci. 2011 Feb;29(1):63-9.

12 Mlynash M, Olivot JM, Tong DC, Lansberg MG, Eyngorn I, Kemp S, et al. Yield of combined perfusion and diffusion MR imaging in hemispheric TIA. Neurology. 2009 Mar;72(13):1127-33.
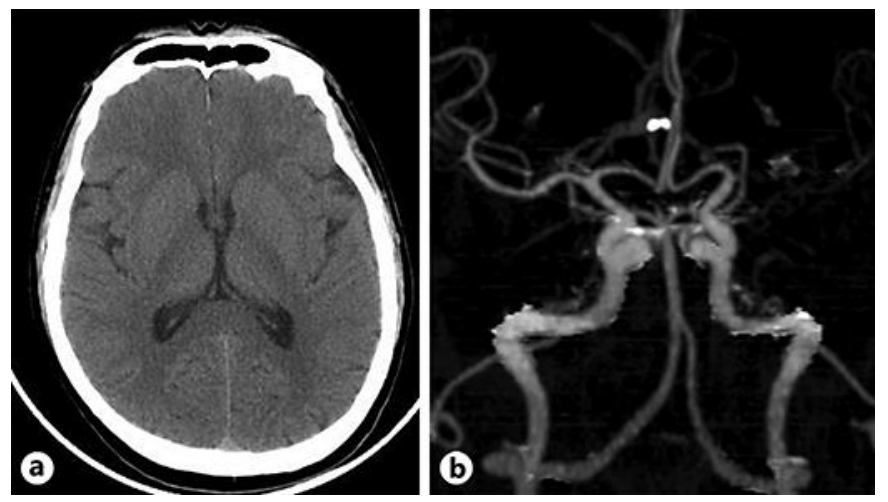

Fig. 1. Angiography of the anterior circulation. a Noncontrast CT with no hemorrhage, ASPECTS of 10. b CT angiography: occlusion of the proximal left MCA artery. ASPECTS, Alberta Stroke Program Early CT Score; CT, computed tomography; MCA, middle cerebral artery. 
Case Reports in Neurology
Case Rep Neurol 2020;12:41-48 DOI: $10.1159 / 000507753$

(c) 2020 The Author(s). Published by S. Karger AG, Basel www.karger.com/crn

Nguyen et al.: Mechanical Thrombectomy in a TIA Patient with Middle Cerebral Artery Occlusion
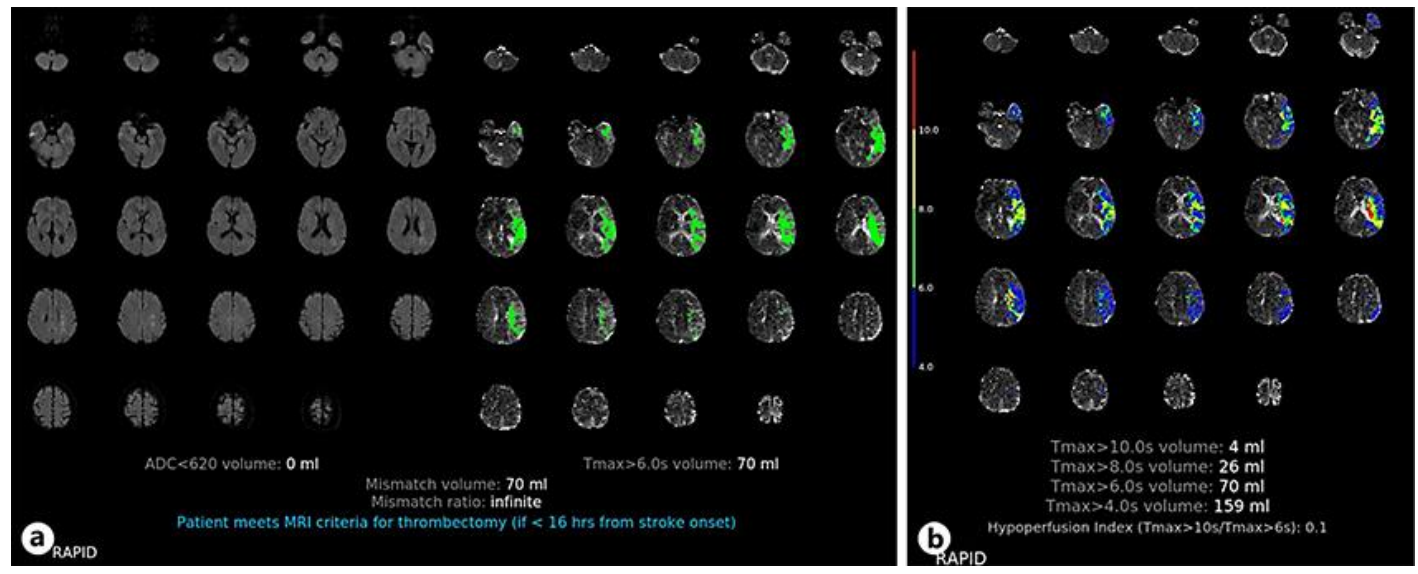

Fig. 2. Perfusion MRI with the RAPID software. a Small diffusion lesion in the left hemisphere and corona radiata with a complete perfusion deficit of the left MCA territory: mismatch volume. $\mathbf{b}$ Levels of Tmax. MCA, middle cerebral artery; MRI, magnetic resonance imaging. 
Case Reports in Neurology

\begin{tabular}{l|l}
\hline Case Rep Neurol 2020;12:41-48 \\
\hline DOI: 10.1159/000507753 & $\begin{array}{l}\text { @ 2020 The Author(s). Published by S. Karger AG, Basel } \\
\text { www.karger.com/crn }\end{array}$ \\
\hline
\end{tabular}

Nguyen et al.: Mechanical Thrombectomy in a TIA Patient with Middle Cerebral Artery Occlusion
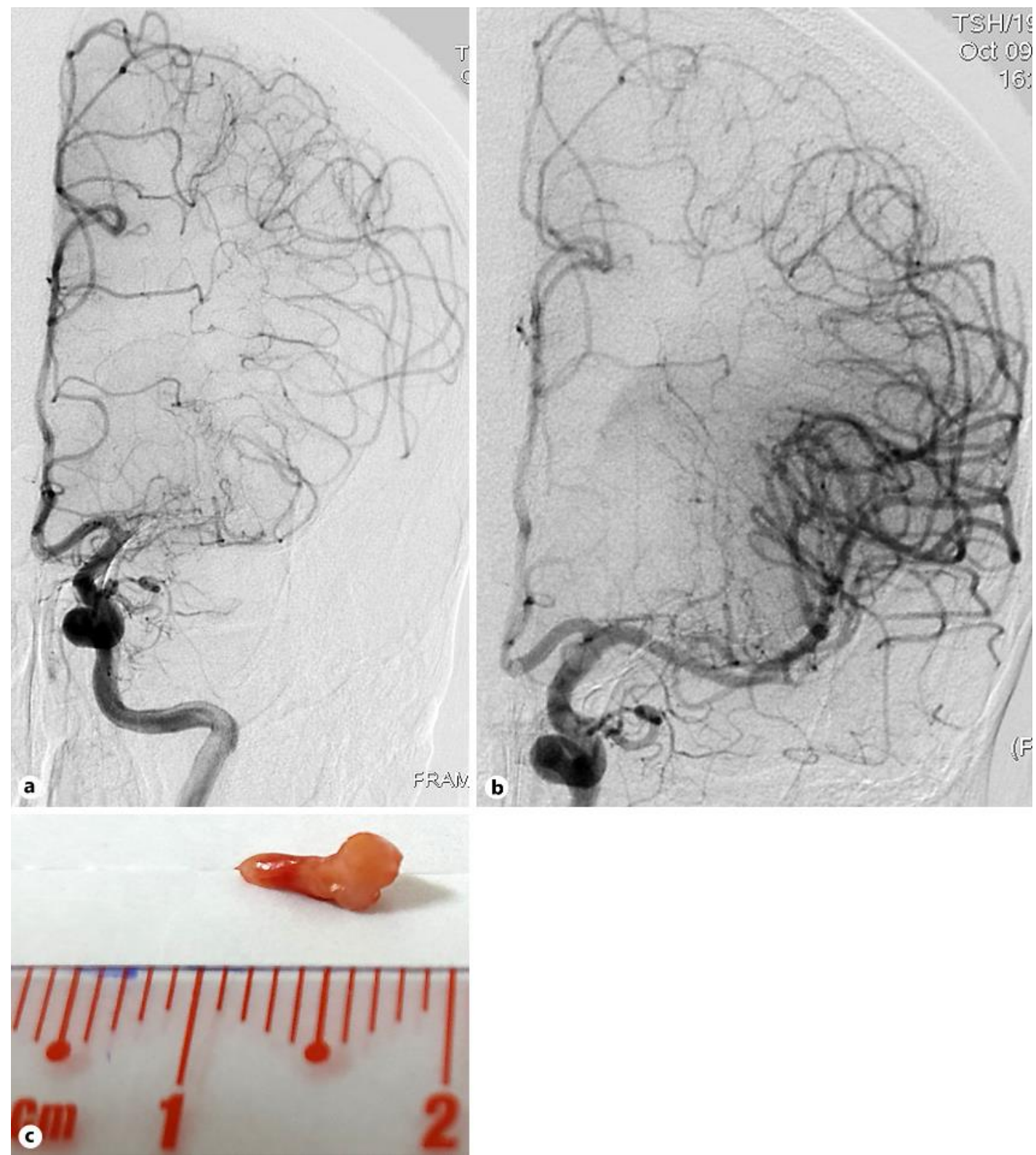

Fig. 3. Before and after MT. a Occlusion of the proximal M1 MCA. b After recanalization: complete reperfusion TICI 3. c Clot specimen removed from the M1 segment. MCA, middle cerebral artery; MT, mechanical thrombectomy. 
Case Reports in Neurology
Case Rep Neurol 2020;12:41-48 DOI: $10.1159 / 000507753$

(c) 2020 The Author(s). Published by S. Karger AG, Basel www.karger.com/crn

Nguyen et al.: Mechanical Thrombectomy in a TIA Patient with Middle Cerebral Artery Occlusion
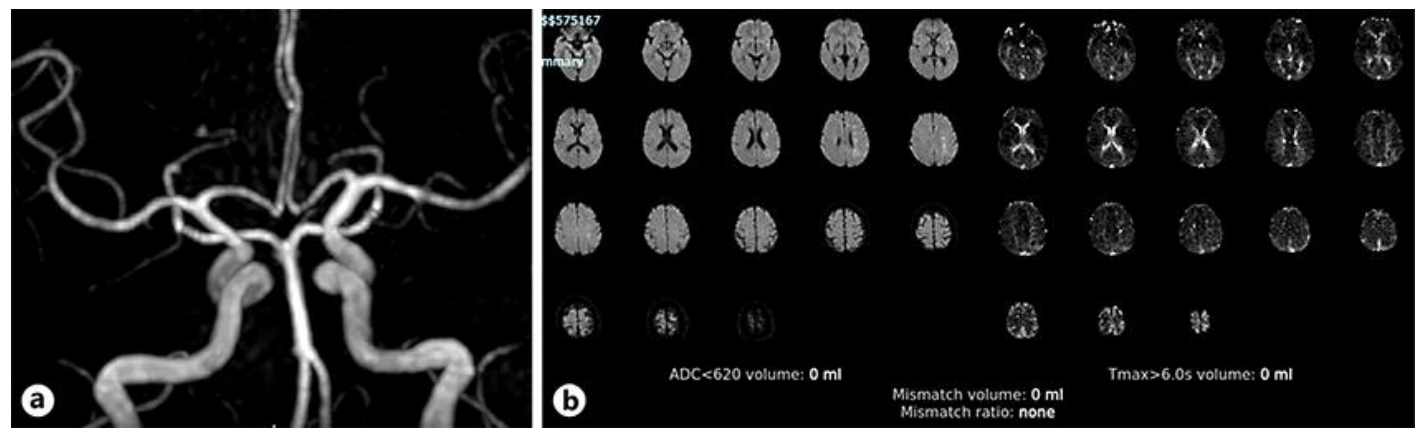

Fig. 4. Twenty-four-hour follow-up perfusion MRI. a Recanalization of the left MCA. b Disappearance of $\mathrm{T}_{\max }$ : no mismatch. MCA, middle cerebral artery; MRI, magnetic resonance imaging. 